\title{
Influence of Finish Rolling Temperature on Microstructure and Mechanical Properties of a 19Cr1.5Mo0.5 W Ferritic Stainless Steel
}

\author{
Hou-Long Liu ${ }^{1} \cdot$ Ling-Ling Liu ${ }^{1} \cdot$ Ming-Yu Ma ${ }^{1} \cdot$ Li-Qing Chen $^{1}$
}

Received: 6 December 2019 / Revised: 9 January 2020 / Published online: 31 March 2020

(c) The Chinese Society for Metals (CSM) and Springer-Verlag GmbH Germany, part of Springer Nature 2020

\begin{abstract}
A 444-type heat-resistant ferritic stainless steel containing $0.05 \mathrm{wt} \% \mathrm{Ce}$ (rare earth element) and $2 \mathrm{wt} \%(\mathrm{Mo}+\mathrm{W}) \mathrm{was}$ adopted as an experimental material to study the effect of finish rolling temperature on microstructure and texture evolution as well as on mechanical properties and formability. The rolling processes contain hot rolling at two different finish rolling temperatures $\left(860^{\circ} \mathrm{C}\right.$ and $\left.770{ }^{\circ} \mathrm{C}\right)$ and annealing, cold rolling and subsequent annealing. It was found that the microstructures after hot rolling and annealing could be refined by lowering finish rolling temperature. The resultant microstructures after cold rolling and annealing were hereditarily refined. Lowering finish rolling temperature can weaken $\alpha$-fiber texture in hotrolled or cold-rolled ferritic stainless steel strip, while $\gamma$-fiber texture in the final product was homogeneously strengthened. Additionally, enhanced mechanical property and formability in terms of strength and average plastic strain ratio could be obtained via decreasing finish rolling temperature.
\end{abstract}

Keywords Ferritic stainless steel $\cdot$ Finish rolling temperature $\cdot$ Microstructure $\cdot$ Texture $\cdot$ Mechanical property $\cdot$ Formability

\section{Introduction}

The low-cost ultra-pure ferritic stainless steels have excellent corrosion durability, thermal fatigue resistance and oxidation resistance at elevated temperatures [1-3]. These advantages make them promising for manufacturing of automotive exhaust manifold. The service temperature of traditional 444 ferritic stainless steels used for exhaust manifold is $\sim 900{ }^{\circ} \mathrm{C}$. However, the need for the vehicle emission standards requires higher emission temperature and the maximum service temperature of exhaust manifold will reach $950-1050{ }^{\circ} \mathrm{C}$, or even up to $1100{ }^{\circ} \mathrm{C}$ [4]. In this case, the materials used for the next generation of automotive exhaust systems should possess excellent anti-oxidation properties and thermal fatigue resistance at elevated temperatures. It was reported that the addition of $\mathrm{W}$ and/or Mo could improve both the creep rupture strength and thermal fatigue resistance of ferritic stainless steel through precipitation and/

Available online at http://link.springer.com/journal/40195.

Li-Qing Chen

lqchen@mail.neu.edu.cn

1 State Key Laboratory of Rolling and Automation, Northeastern University, Shenyang 110819, China or solid-solution strengthening effects [5-7]. Meanwhile, it was confirmed that the oxide film became uniform and compact, and the number of defects at the oxide/metal interface was significantly reduced such that it displayed good scale adhesion after $\mathrm{Ce}$ addition $[8,9]$. In order to improve the high-temperature oxidation resistance and thermal mechanical fatigue behavior of ferritic stainless steel, alloying with rare earth element $\mathrm{Ce}$ and higher melting-point metals $\mathrm{W}$ and/or Mo may be an effective way.

Generally, the formability of ferritic stainless steel should be taken into consideration in practical application and this can be improved by several approaches, such as the chemical composition design [10], solidified microstructure control [11], and optimization of rolling schedules [12-14]. Regarding the new developed heat-resistant ferritic stainless steel containing $\mathrm{W}+\mathrm{Mo}$ and $\mathrm{Ce}$, however, the influence of hot rolling processes on formability and mechanical properties remains unclear and need to have a deep understanding. The aim of this study is to explore the effect of rolling processes, particularly finish rolling temperature, on the microstructure and texture evolution of $19 \mathrm{Cr} 1.5 \mathrm{Mo} 0.5 \mathrm{~W}$ ferritic stainless steel as well as on its mechanical properties and formability. The enhanced formability and mechanical properties were also discussed on the basis of microstructural and texture evolution in association with the rolling processes. 


\section{Experimental}

The chemical composition of experimental steel is listed in Table 1. The steel ingot was prepared in a vacuum induction furnace and forged into slab with $50 \mathrm{~mm}$ thickness after heating at $1180^{\circ} \mathrm{C}$ for $2 \mathrm{~h}$. After reheating at $1200{ }^{\circ} \mathrm{C}$ and soaked for $1 \mathrm{~h}$, the slabs were hot-rolled to $5 \mathrm{~mm}$ thickness wherein the finish rolling temperatures were controlled at $860{ }^{\circ} \mathrm{C}$ and $770{ }^{\circ} \mathrm{C}$. Then they were air-cooled and followed by annealing at $1050{ }^{\circ} \mathrm{C}$ for $5 \mathrm{~min}$. Finally, the plates were cold-rolled to $1 \mathrm{~mm}$ thickness and subsequently annealed at $1050{ }^{\circ} \mathrm{C}$ for 1 min followed by air cooling.

Room-temperature tensile test of the final sheets was carried out by INSTRON 4206 tensile testing machine according to the National Standard of the PR China, GB/T 228.1-2010 [15]. The crosshead speed of $3 \mathrm{~mm} / \mathrm{min}$ was employed for room temperature tensile test to determine mechanical properties including the tensile strength, yield strength, and elongation. The formability characterized by plastic strain ratio $(r)$, which denotes the ratio of true strain in the width direction to the thickness direction, was measured according to GB/T50272016 [16]. A mean value of plastic strain ratio $r_{\mathrm{m}}$ is calculated by Eq. (1) [17]:

$r_{\mathrm{m}}=\left(r_{0}+2 r_{45}+r_{90}\right) / 4$

The anisotropy of plastic strain ratio is called $\Delta r$ and calculated as follows:

$\Delta r=\left(r_{0}-2 r_{45}+r_{90}\right) / 2$

where the subscripts $0^{\circ}, 45^{\circ}$, and $90^{\circ}$ refer to the direction at which the sample was taken relative to the rolling direction. The formability of ferritic stainless sheet can be evaluated based on these data. In addition, the surface roughness $R_{\mathrm{a}}$ and maximum surface roughness $R_{\mathrm{t}}$ of the final sheets strained by $15 \%$ along the rolling direction were measured using a TR 300 roughness measuring instrument.

The specimens for texture analysis were mechanically polished and etched in a solution of dilute hydrochloric acid $(\mathrm{HCl})$ to remove the deformed layer. In this experiment, all the textures were measured at the center layer of the sheets to characterize texture evolution by the Bruker D8 Discover X-ray diffraction with Co $K \alpha$ radiation. The texture analysis was performed via the measurement of three incomplete pole figures $\{110\},\{200\}$, and $\{211\}$ on the central layer of the sample, and the orientation distribution function (ODF) was calculated for these three pole figures using the series expansion method with $L_{\max }=22$. The ODF was presented as plots of $\varphi_{2}=45^{\circ}$ sections in Euler space defined by Euler angles $\left(\varphi_{1}, \Phi, \varphi_{2}\right)$. Figure 1 shows the position of typical orientations in $\varphi_{2}=45^{\circ}$ ODF section that contains the texture components discussed in this paper. The orientation density intensity $f(\mathrm{~g})$ is plotted against Euler angles $\varphi_{1}$ and $\Phi$.

The metallographic specimens were etched in a solution of $5 \mathrm{~g} \mathrm{FeCl}_{3}+50 \mathrm{ml} \mathrm{HCl}+150 \mathrm{ml} \mathrm{H}_{2} \mathrm{O}$, and an optical microscope (BX53M) was used for microstructural observation and analysis. The average grain size was measured using the mean linear intercept method. The crystal orientation and grain size distribution of the samples were measured using an FEI Quanta 600 scanning electron microscope (SEM) equipped with electron backscattered diffraction (EBSD) and TSL OIM 4.6 data acquisition and analysis. To determine the grains based on the EBSD technology, boundary fragments above misorientation angle $\left(10^{\circ}\right)$ between the neighbored grains were defined as grain boundaries. In this study, EBSD was applied on the longitudinal sections as defined by the rolling direction (RD) and the normal direction (ND).

\section{Results and Discussion}

\subsection{Microstructure and Texture Evolution}

The optical micrographs for microstructures in hot-rolled and annealed sheets are shown in Fig. 2. The microstructures in these two steels were both elongated along the rolling direction after hot rolling. However, the banded structures in the hot-rolled plate with a finish rolling temperature of $770{ }^{\circ} \mathrm{C}$ were narrower than the other one, which indicated that work hardening was severer for the hot-rolled plate with low finish rolling temperature. After annealing at $1050{ }^{\circ} \mathrm{C}$ for $5 \mathrm{~min}$, the microstructures in the annealed sheets consisted of a single ferritic phase and the average grain size of the annealed sheets with finish rolling temperature of 860 and $770{ }^{\circ} \mathrm{C}$ was $62.3 \mu \mathrm{m}, 50.4 \mu \mathrm{m}$, respectively. The recrystallized grains in the annealed sheet with lower finish rolling temperature were finer compared with that in the annealed sheet with higher finish rolling temperature.

Figure 3 shows microstructures in cold-rolled sheets and corresponding annealed sheets. The microstructures in these two cold-rolled sheets were elongated. Nevertheless, there were narrower and more banded structures in the cold-rolled plate with lower finish rolling temperature, leading to the refined recrystallized grains in the subsequent annealed sheet. The average grain size of the annealed sheets with finish

Table 1 Chemical composition of the experimental steel (wt\%)

\begin{tabular}{llllllllll}
\hline $\mathrm{C}$ & $\mathrm{Si}$ & $\mathrm{Mn}$ & $\mathrm{Cr}$ & $\mathrm{Nb}$ & $\mathrm{Ti}$ & $\mathrm{N}$ & $\mathrm{Mo}$ & $\mathrm{W}$ & $\mathrm{Ce}$ \\
\hline$<0.01$ & 0.44 & 0.34 & 19.6 & 0.47 & 0.14 & $<0.009$ & 1.55 & 0.45 & 0.05 \\
\hline
\end{tabular}




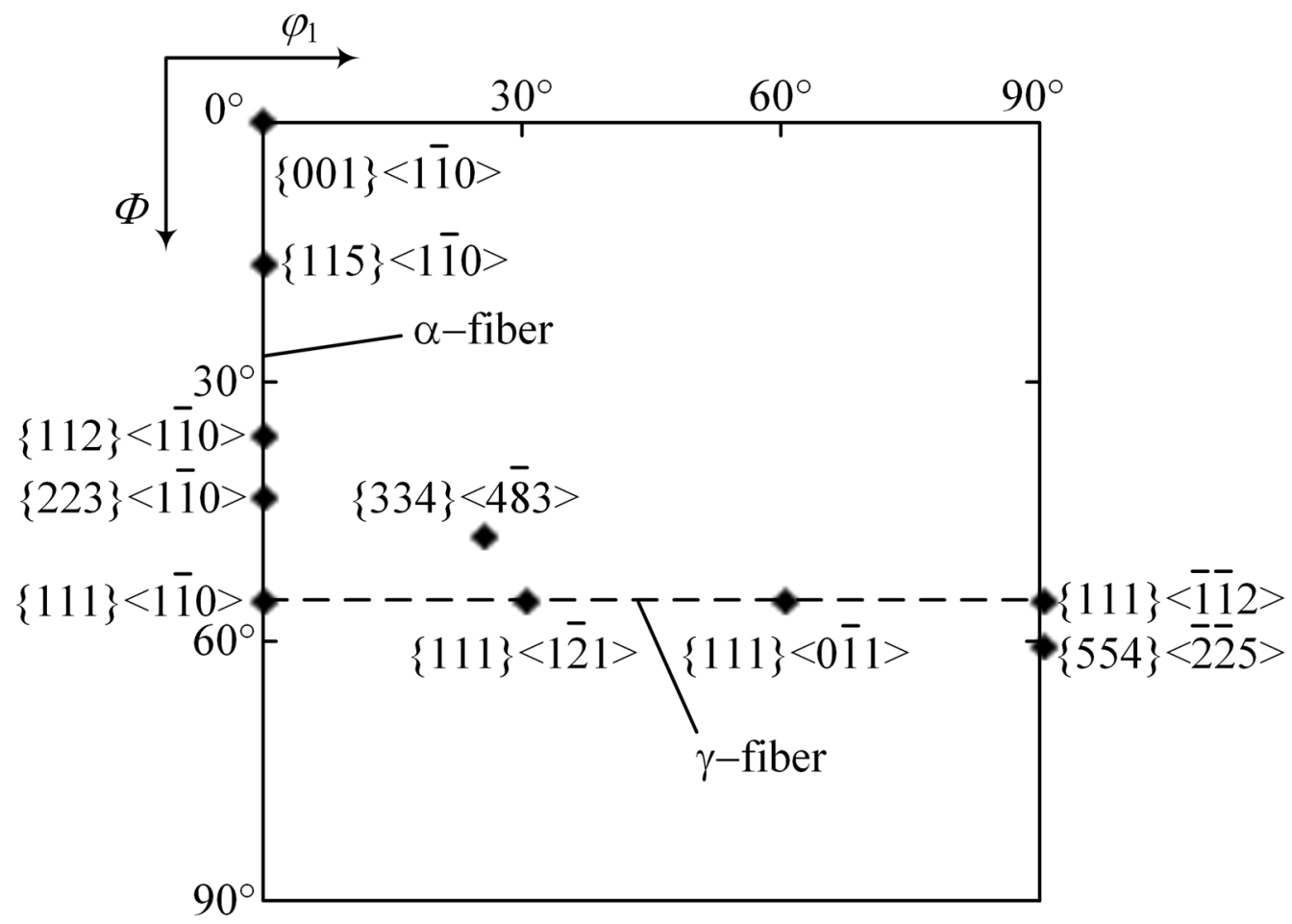

Fig. 1 Main orientations of ferritic stainless steel in $\varphi_{2}=45^{\circ} \mathrm{ODF}$ section

rolling temperature of 860 and $770{ }^{\circ} \mathrm{C}$ was $33.4 \mu \mathrm{m}, 20.8 \mu \mathrm{m}$, respectively.

When finish rolling temperature decreased, the dynamic recovery was inhibited, and work hardening and deformation energy storage were increased, which provided the larger number of nucleation sites and the driving force for recrystallization. The microstructures in the hot-rolled plate were refined after annealing. After cold rolling, it could be inherited to the microstructures in the cold-rolled sheet leading to refined grains in the final plate.

Figure 4 displays the textures of the central layers in the hot-rolled sheets and annealed sheets with various finish rolling temperatures. Obviously, the textures of the central layer in the hot-rolled steels were mainly composed of typical $\alpha$-fiber. The intensity of $\alpha$-fiber texture in the hot-rolled plate with a finish rolling temperature of $860{ }^{\circ} \mathrm{C}$ (Fig. 4a) was stronger compared with that of hot-rolled sheet with a hot rolling finish temperature of $770{ }^{\circ} \mathrm{C}$ (Fig. 4b). After annealing of the hot-rolled sheet with finish rolling temperature of $860{ }^{\circ} \mathrm{C}$ (Fig. $4 \mathrm{c}$ ), the $\alpha$-fiber texture of $\{115\}<1 \overline{1}$ $0>$ shifted to $\{223\}<1 \overline{1} 0>$ and the corresponding intensity declined compared with that of $\{115\}<1 \overline{10}>$, and the component of $\gamma$-fiber at $\{111\}<0 \overline{1} 1>$ distinctly appeared in the center layer of the hot-rolled sheet after annealing, while the annealed sample with a finish rolling temperature of $770{ }^{\circ} \mathrm{C}$ (Fig. 4d) demonstrated that the intensity of overall textures was weak. The reason may be that the deformation energy storage of ferritic grain in hot-rolled sheet was increased though decreasing finish rolling temperature, which made recrystallization easier for the various orientation grains.

Figure 5 shows the textures of the central layers in coldrolled sheets and annealed sheets with different hot rolling processes. The textures of cold-rolled sheets were mainly composed of $\alpha$-fiber and $\gamma$-fiber. The maximum intensity of $\alpha$-fiber in two cold-rolled sheets was both located at $\{223\}$ $<1 \overline{1} 0>$, but the intensity of $\alpha$-fiber in the cold-rolled sheet with a finish rolling temperature of $860{ }^{\circ} \mathrm{C}$ was stronger than that in the cold-rolled sheet with a finish rolling temperature of $770{ }^{\circ} \mathrm{C}$. Furthermore, the maximum intensity of $\gamma$-fiber in the cold-rolled sheet with high finish rolling temperature was located at $\{111\}<\overline{12} 3>$, while the maximum intensity of $\gamma$-fiber in the cold-rolled sheet with low finish rolling temperature was located at $\{111\}<0 \overline{1} 1>$ and slightly increased compared with that of the cold-rolled sheet with high finish rolling temperature. After annealing, the recrystallization texture of the annealed sheet with a finish rolling temperature of $860^{\circ} \mathrm{C}$ was mainly composed of near $\gamma$-fiber at $\{111\}$ $<1 \overline{2} 1>$ and $\{111\}<\overline{11} 2>$, and the maximum intensity was 

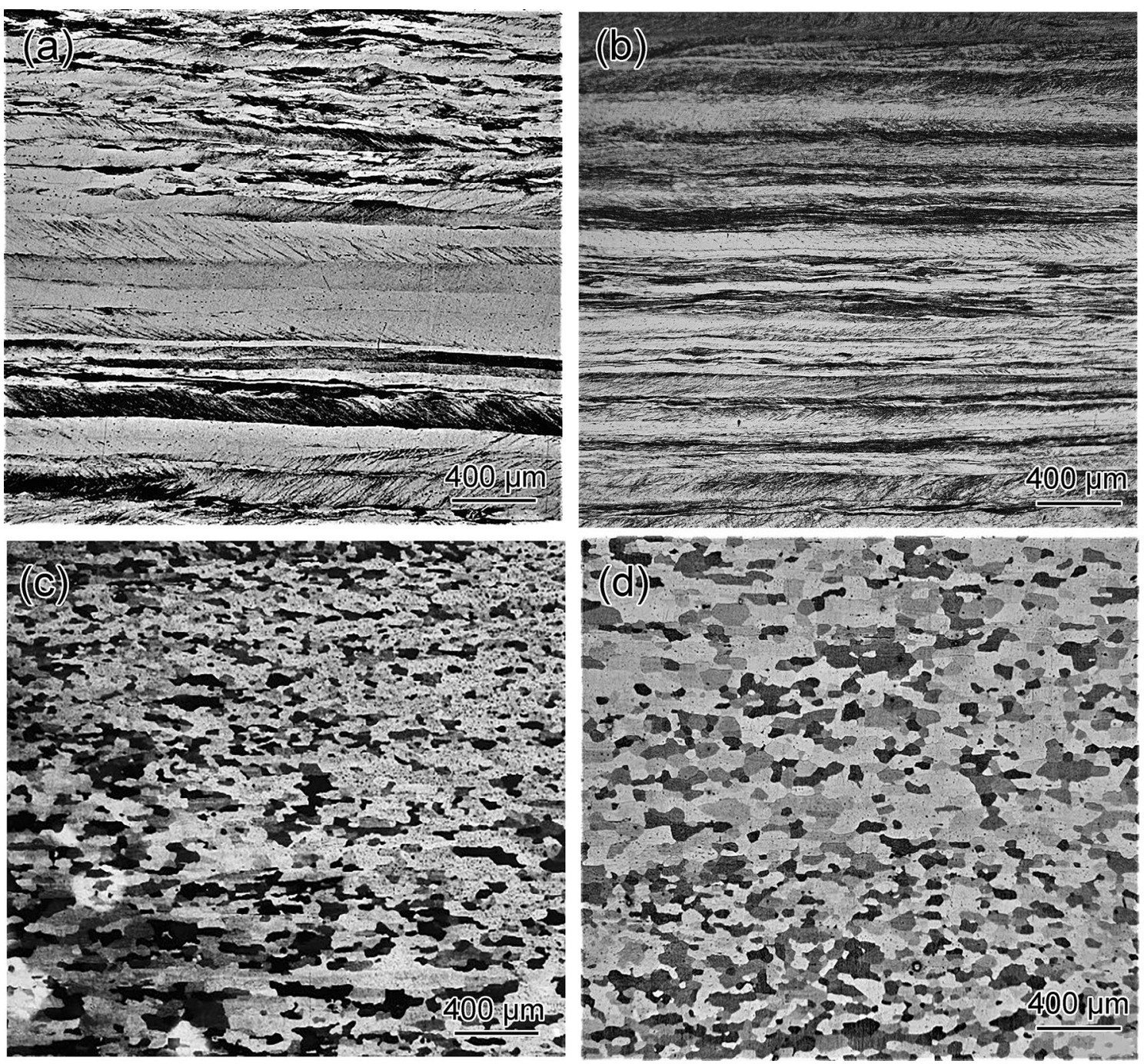

Fig. 2 Optical micrographs for microstructures in the hot-rolled sheet $\mathbf{a}$ and annealed sheet $\mathbf{c}$ with finish rolling temperature of $860{ }^{\circ} \mathrm{C}$ and the hot-rolled sheet $\mathbf{b}$, annealed sheet $\mathbf{d}$ with finish rolling temperature of $770{ }^{\circ} \mathrm{C}$

about $f(g)_{\max }=7.5$. The other one displayed a similar distribution of $\gamma$-fiber texture and the maximum intensity of $\{111\}<\overline{11} 2>$ was about $f(g)_{\max }=10.1$.

During rolling process, the crystal rotates along the following path: $\{001\}<1 \overline{1} 0>\rightarrow\{115\}<1 \overline{1} 0>\rightarrow\{112\}<1 \overline{1}$ $0>\rightarrow\{223\}<1 \overline{1} 0>[18,19]$. Therefore, the textures in hotrolled and annealed sheet can be inherited to cold-rolled sheet to a certain extent. The stronger the intensity of $\alpha$-fiber texture in hot-rolled and annealed sheet was, the stronger the intensity of $\alpha$-fiber texture in cold-rolled sheet was. During annealing the cold-rolled sheet, the recrystallization grains with $\gamma$-fiber orientation grew up gradually and annexed the grain with $\alpha$-fiber orientation [20]. Therefore, a weak $\alpha$-fiber texture and a strong $\gamma$-fiber texture intensity in cold-rolled sheet was beneficial to the formation of $\gamma$-fiber recrystallization texture after annealing. Abreu et al. [13] investigated the effect of high-temperature annealing on texture of an AISI444 ferritic stainless steel, and the results also showed that the intensity of $\gamma$-fiber texture in cold-rolled and annealed sheet increased with the increase in the intensity of $\gamma$-fiber texture in cold-rolled sheet.

The grain orientation and grain size distribution of the longitudinal section in cold-rolled sheet after annealing at $1050{ }^{\circ} \mathrm{C}$ for $1 \mathrm{~min}$ examined by EBSD are shown in Fig. 6. When finish rolling temperature was $860{ }^{\circ} \mathrm{C}$, the distribution of blue and near blue grains in the annealed 

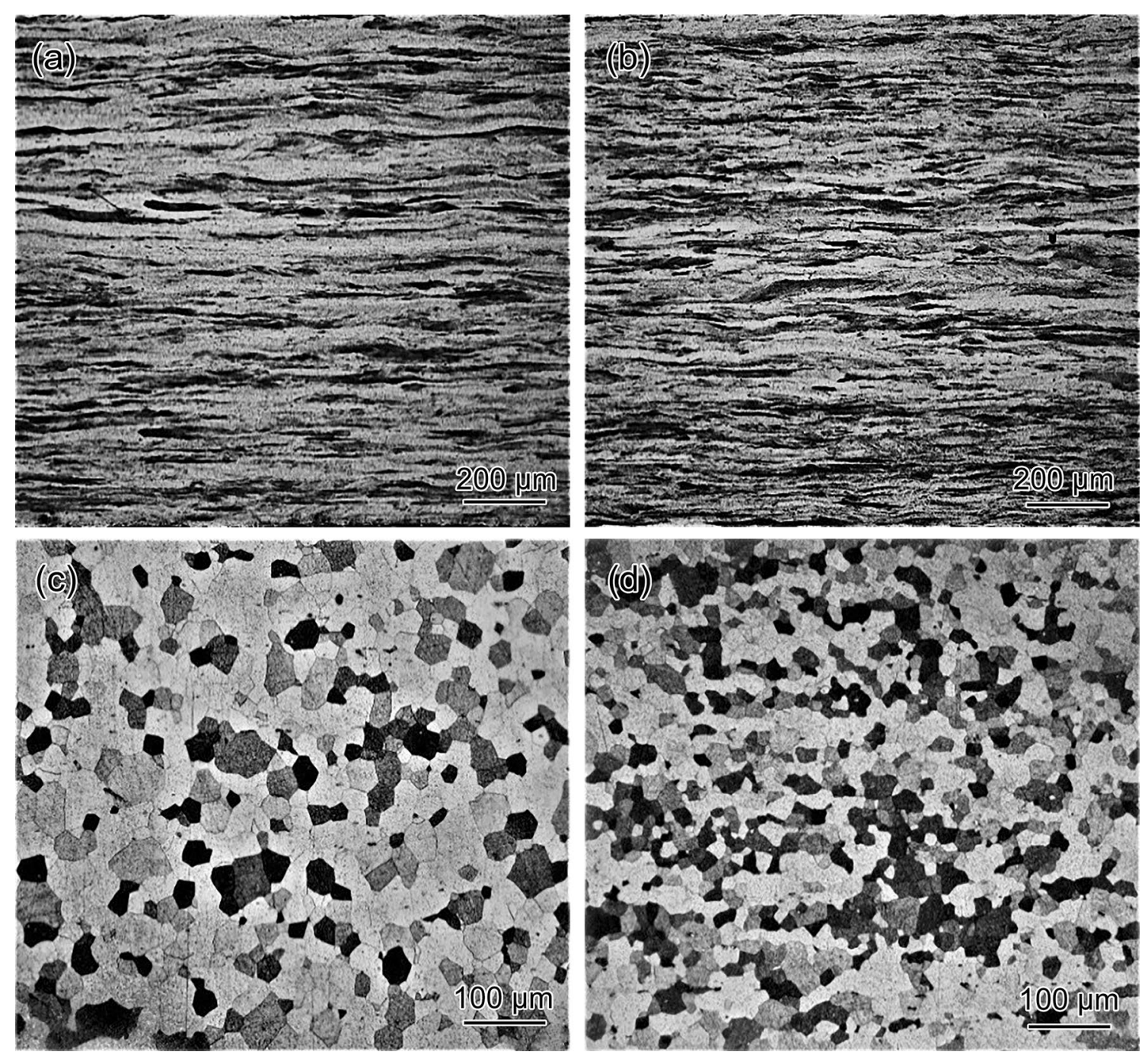

Fig. 3 Optical micrographs for the cold-rolled sheet $\mathbf{a}$ and annealed sheet $\mathbf{c}$ with a finish rolling temperature of $860{ }^{\circ} \mathrm{C}$ and the cold-rolled sheet $\mathbf{b}$, annealed sheet $\mathbf{d}$ with a finish rolling temperature of $770{ }^{\circ} \mathrm{C}$

sheet was obviously uneven, and those in the middle area were relatively more than that nearby the surface layer. The grain size of the annealed microstructure was ranging from 11 to $85 \mu \mathrm{m}$. Yet, it can be clearly observed that the different orientation grains in the annealed sheet with a finish rolling temperature of $770{ }^{\circ} \mathrm{C}$ were distributed uniformly in the direction of the thickness. Moreover, the grain size distribution was compact with the range from 9 to $64 \mu \mathrm{m}$. It can be concluded that the decrease in finish rolling temperature can make the distributions of various orientation grains and grain size more homogeneous in cold-rolled sheet after annealing.

\subsection{Mechanical Properties and Formability}

The engineering stress-strain curves of the cold-rolled and annealed sheet under various rolling conditions are presented in Fig. 7. The mechanical properties of the final products are also shown in Table 2 . With the decrease in finish rolling temperature, both of the yield strength and tensile strength of the final sheets were increased. However, the changes of the yield strength ratio and elongation were not obvious. An increase in the strength can be attributed to the grain refinement by lowering finish rolling temperature. 

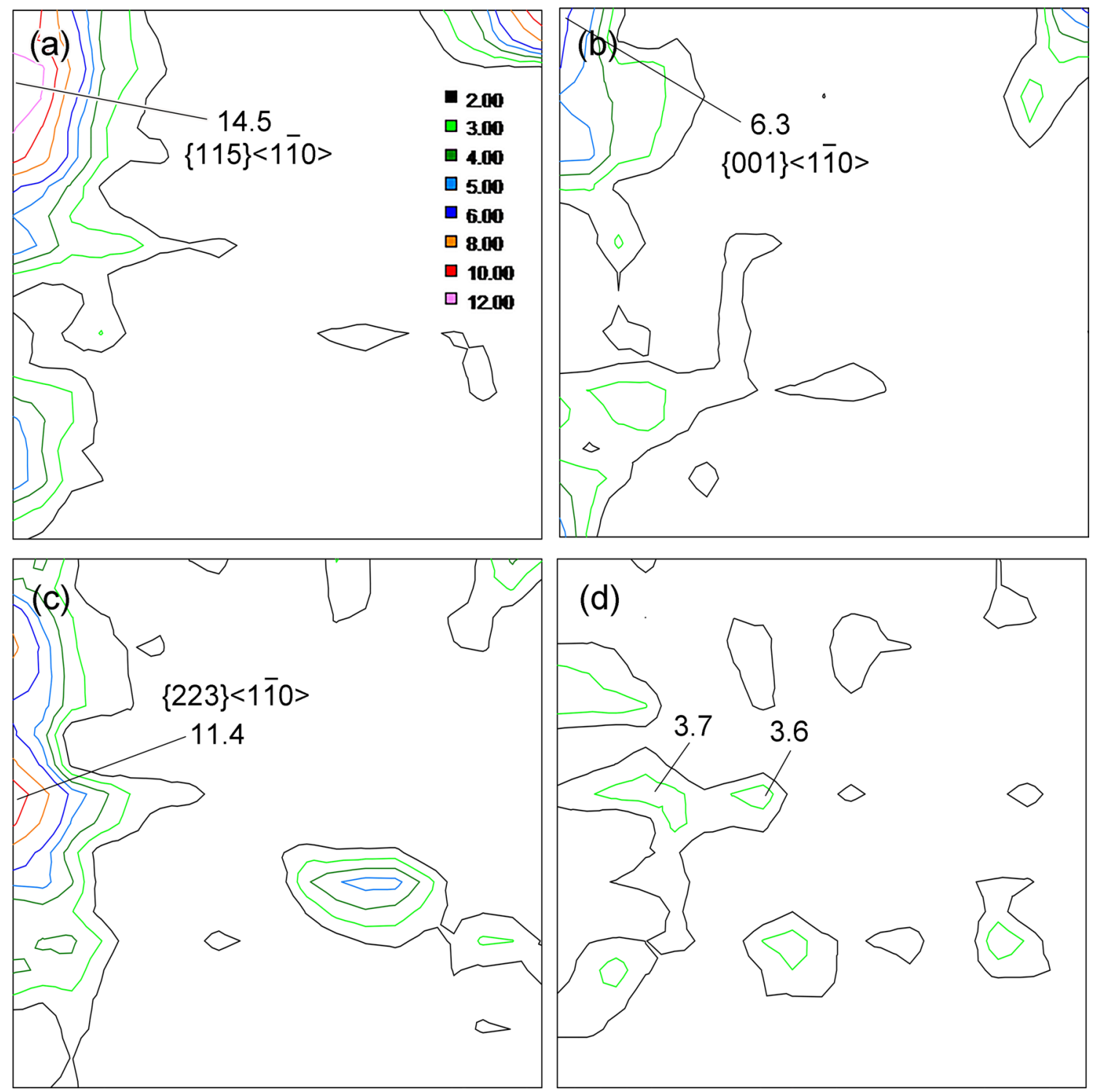

Fig. 4 Constant $\varphi_{2}=45^{\circ}$ ODF sections for the hot-rolled sheet a and annealed sheet $\mathbf{c}$ with finish rolling temperature of $860{ }^{\circ} \mathrm{C}$ and the hotrolled sheet $\mathbf{b}$, annealed sheet $\mathbf{d}$ with finish rolling temperature of $770{ }^{\circ} \mathrm{C}$

Table 3 presents the formability of cold-rolled sample after annealing. Work hardening index $n$ of two final sheets was equal in value. The $r$ value of annealed sheet in different directions was increased with the decrease in finishing rolling temperature, especially significantly increased by $43.2 \%$ in $45^{\circ}$ directions. Not only was $r_{\mathrm{m}}$ value enhanced, $\Delta r$ value was also reduced by $61.6 \%$. Deep-drawing ability can be evaluated by $r_{\mathrm{m}}$ and $\Delta r$ value and the condition leading to a better deep-drawing operation is that there is a higher $r_{\mathrm{m}}$ value and $\Delta r$ values is close to zero [21,22]. Hence, the final sheet with a finish rolling temperature of $770{ }^{\circ} \mathrm{C}$ possesses a better deep-drawing ability. The surface roughness profiles of annealed sheets after $15 \%$ tensile deformation are shown in Fig. 8 and the corresponding values of surface roughness are presented in Table 3 . Both of the average surface roughness $R_{\mathrm{a}}$ and maximum surface roughness $R_{\mathrm{t}}$ 

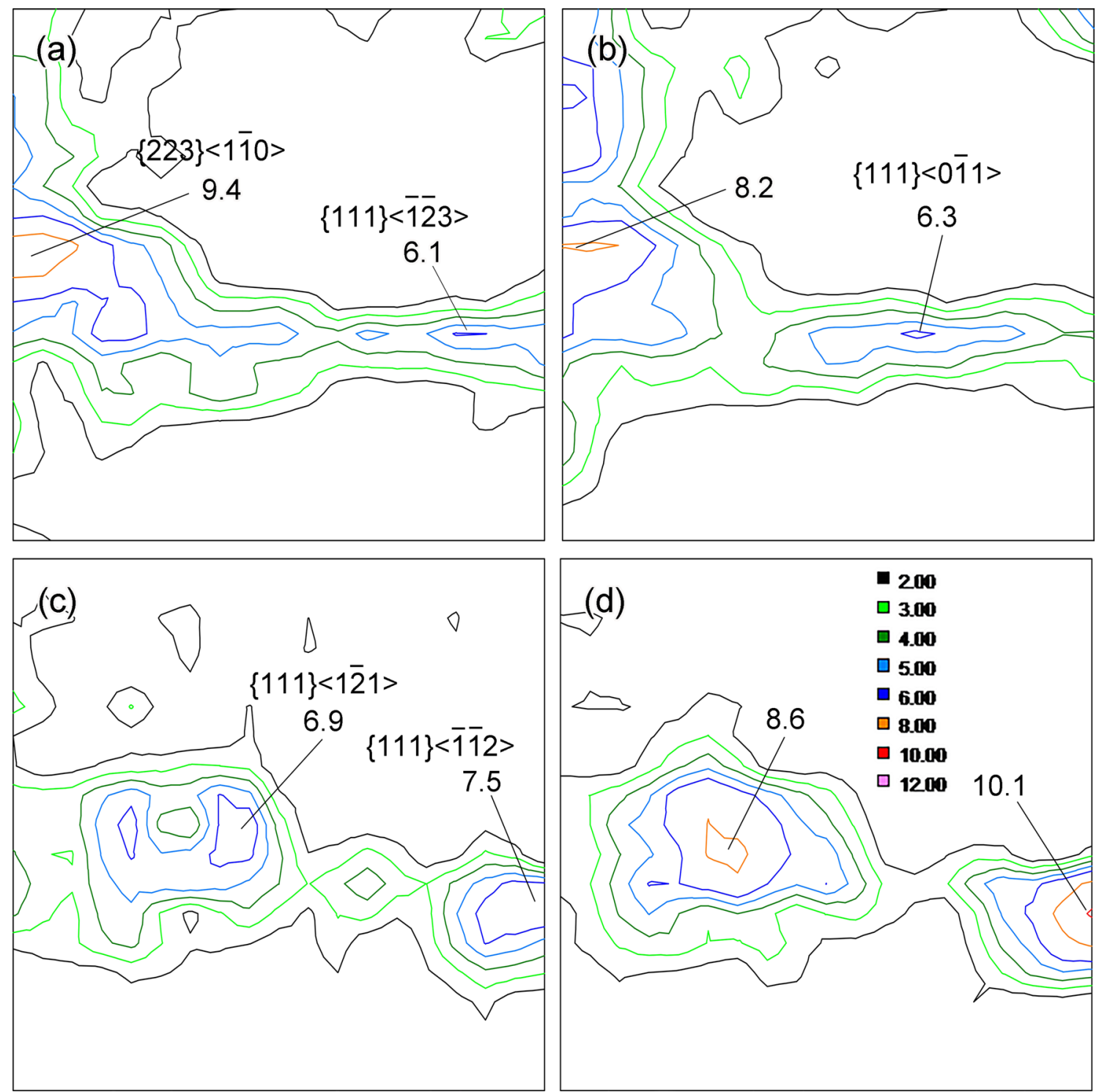

Fig. 5 Constant $\varphi_{2}=45^{\circ}$ ODF sections for cold-rolled sheet a and annealed sheet $\mathbf{c}$ with a finish rolling temperature of $860{ }^{\circ} \mathrm{C}$ and the coldrolled sheet $\mathbf{b}$, annealed sheet $\mathbf{d}$ with a finish rolling temperature of $770{ }^{\circ} \mathrm{C}$ 

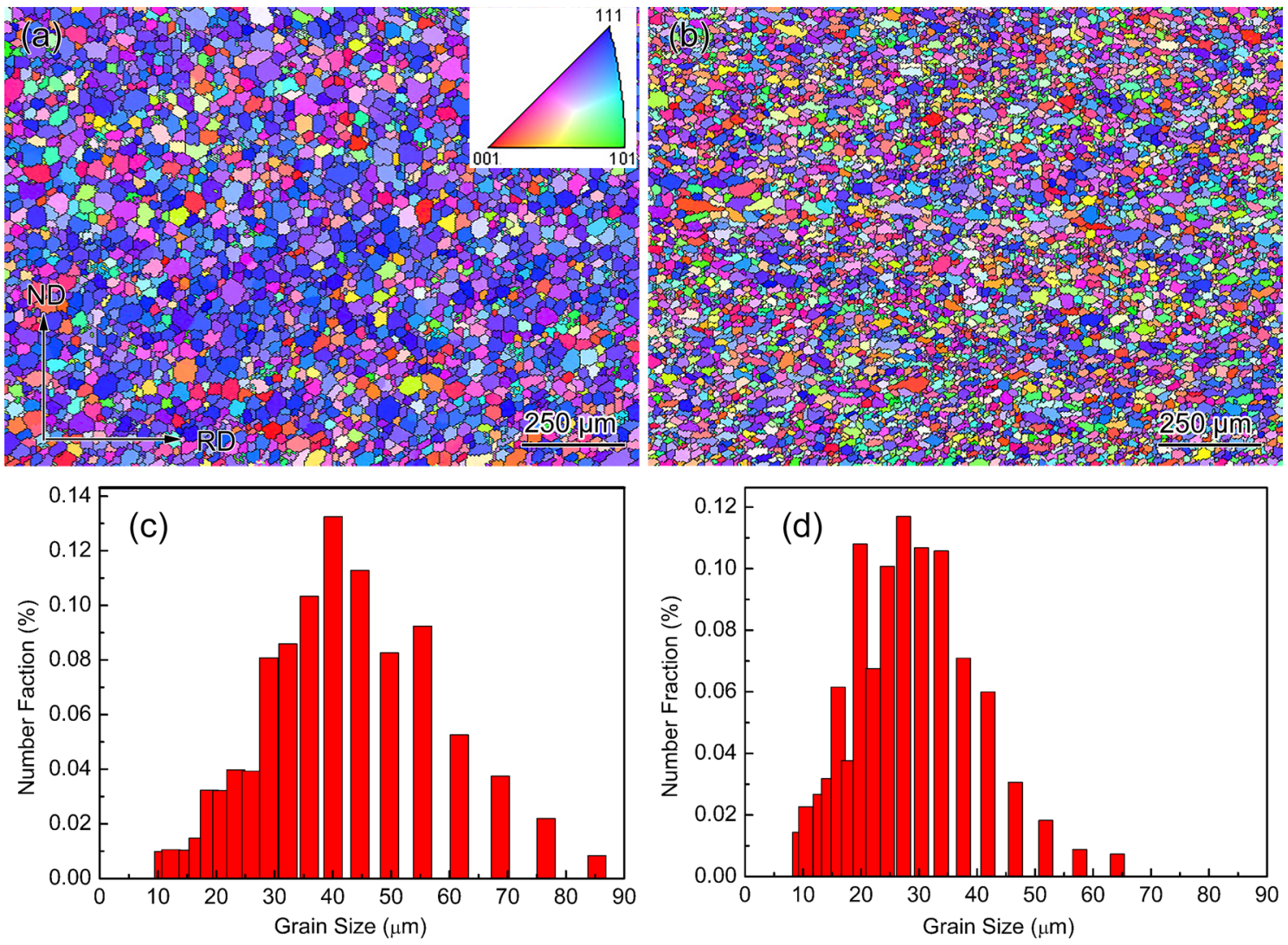

Fig. 6 Crystal orientation maps and grain size distribution of the annealed sheet with finish rolling temperature of $860{ }^{\circ} \mathrm{C} \mathbf{a}, \mathbf{c}, 770{ }^{\circ} \mathrm{C} \mathbf{b}, \mathbf{d}$

of annealed sheet were significantly reduced by lowering finishing rolling temperature, so that the surface quality of the final sheet was improved.

It was confirmed that high plastic strain ratio and low anisotropy were displayed by materials having a very intense $\gamma$-fiber texture at $\{111\}<1 \overline{2} 1>$ and $\{111\}<\overline{11} 2>$ in steel sheet $[23,24]$ and this phenomenon was advantageous for drawing operations and the forming limits [25, 26]. In addition, the surface defect problem of ridging was unfavorable for surface appearance and further drawing operations. Shin et al. [27] suggested that the ridging of ferritic stainless steel mainly resulted from different plastic deformations of the grains with different crystal orientations when subjected to tension, and the longitudinal alignment of grain clusters could also arouse the formation of a corrugated surface [28, 


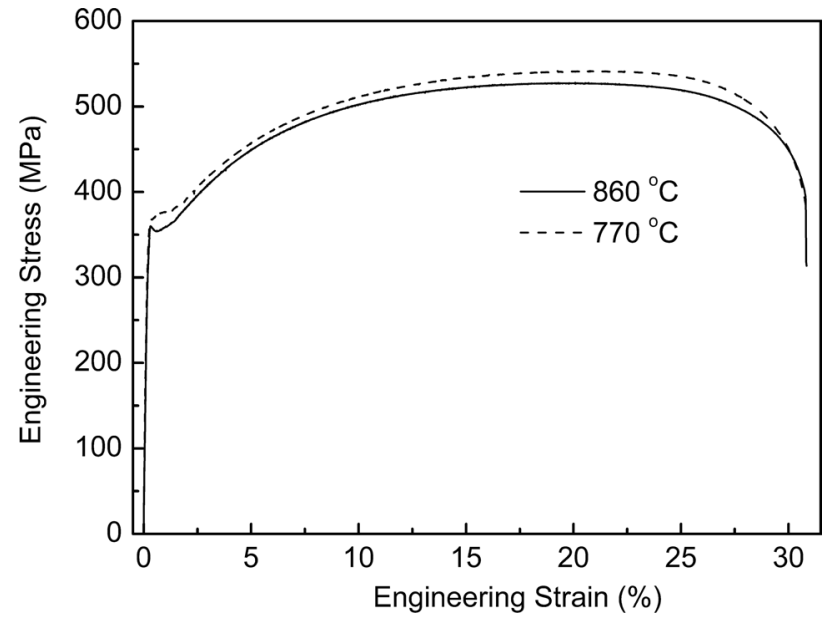

Fig. 7 Engineering stress-strain curves of the final products with different finish rolling temperatures

Table 2 Mechanical properties for cold-rolled and annealed sheets under two hot rolling conditions

\begin{tabular}{lllll}
\hline $\begin{array}{l}\text { Finish rolling } \\
\text { temperature } \\
\left({ }^{\circ} \mathrm{C}\right)\end{array}$ & $\begin{array}{l}\text { Yield } \\
\text { strength } \\
(\mathrm{MPa})\end{array}$ & $\begin{array}{l}\text { Tensile } \\
\text { strength } \\
(\mathrm{MPa})\end{array}$ & Elongation $(\%)$ & $\begin{array}{l}\text { Yield } \\
\text { strength } \\
\text { ratio }\end{array}$ \\
\hline 860 & 354 & 527 & 32.1 & 0.67 \\
770 & 367 & 542 & 32 & 0.68 \\
\hline
\end{tabular}

29]. Moreover, Ma et al. [30] also revealed that the grain refinement was effective in reducing the ridging height of ferritic stainless steel during the forming process. From this work, we can understand that the formability of ferritic stainless steel can be significantly improved as long as high intensity $\gamma$-fiber texture, refinement of microstructure and dispersed distribution of recrystallization grains with various orientations were developed after cold rolling and annealing.

\section{Conclusions}

(1) For $19 \mathrm{Cr} 1.5 \mathrm{Mo} 0.5 \mathrm{~W}$ heat-resistant ferritic stainless steel, lowering finish rolling temperature can refine microstructure in the final annealed sheet and increase the yield and tensile strengths. It can also make the grain distribution of various orientations homogeneous along the direction of thickness.

(2) The intensity of $\alpha$-fiber texture in hot-rolled sheet can be efficiently reduced by decreasing finishing rolling temperature. This feature can be inherited to coldrolled sheet, resulting in an increase in the intensity of $\gamma$-fiber texture after annealing.

(3) The final plate with a finish rolling temperature of $770{ }^{\circ} \mathrm{C}$ exhibited excellent formability due to the occurrence of strong $\gamma$-fiber texture and dispersed distribution of recrystallized grains with various orientations.
Table 3 Formability of the final sheets with two hot rolling processes

\begin{tabular}{lllllllll}
\hline $\begin{array}{l}\text { Finish rolling tem- } \\
\text { perature }\left({ }^{\circ} \mathrm{C}\right)\end{array}$ & $r_{0}$ & $r_{45}$ & $r_{90}$ & $r_{\mathrm{m}}$ & $\Delta r$ & $n$ & $R_{\mathrm{a}}(\mu \mathrm{m})$ & $R_{\mathrm{t}}(\mu \mathrm{m})$ \\
\hline 860 & 1.64 & 0.95 & 1.36 & 1.36 & 0.82 & 0.21 & 0.538 & 4.138 \\
770 & 1.84 & 1.36 & 1.51 & 1.52 & 0.32 & 0.21 & 0.352 & 2.673 \\
\hline
\end{tabular}
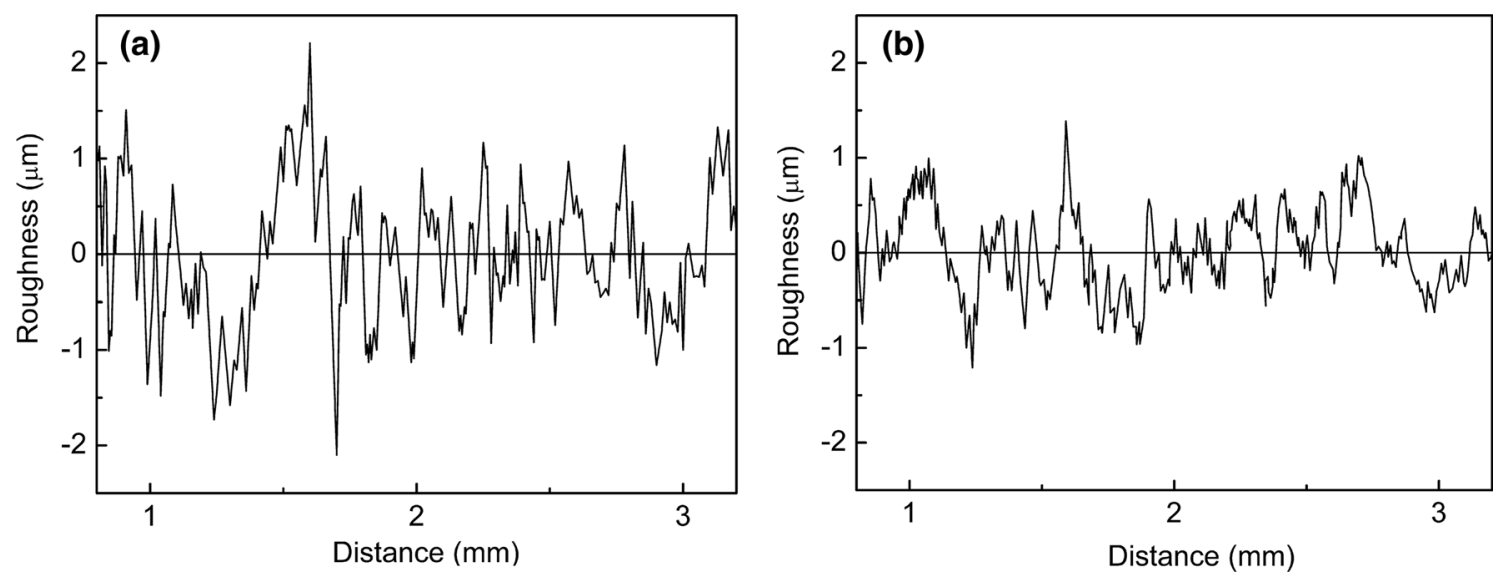

Fig. 8 Surface roughness profiles of the final annealed plates with finish rolling temperature $860{ }^{\circ} \mathrm{C} \mathrm{a}, 770{ }^{\circ} \mathrm{C} \mathrm{b}$ 
Acknowledgement The authors gratefully acknowledge the joint financial support from the National Natural Science Foundation of China and Baowu Steel Group Co., Ltd. (Grant No. U1660205).

\section{References}

[1] Y. Bai, T. He, D. Guo, X.T. Liu, F.Y. Shao, Y.D. Liu, Acta Metall. Sin. -Engl. Lett. 32, 1362 (2019)

[2] M.Y. Ma, C.L. He, L.Q. Chen, L.L. Wei, R.D.K. Misra, Corros. Eng. Sci. Technol. 53, 199 (2018)

[3] A. Safikhani, M. Aminfard, Int. J. Hydrogen Energy 39, 2286 (2014)

[4] H.L. Liu, M.Y. Ma, L.L. Liu, L.L. Wei, L.Q. Chen, J. Iron. Steel Res. Int. 26, 425 (2019)

[5] N. Fujita, K. Ohmura, A. Yamamoto, Mater. Sci. Eng. A 351, 272 (2003)

[6] Y.T. Chiu, C.K. Lin, J. Power Sources 198, 149 (2012)

[7] J. Froitzheim, G.H. Meier, L. Niewolak, P.J. Ennis, H. Hattendorf, L. Singheisera, W.J. Quadakker, J. Power Sources 178, 163 (2008)

[8] L.L. Wei, J.H. Zheng, L.Q. Chen, R.D.K. Misra, Corros. Sci. 142, 79 (2018)

[9] L.L. Wei, L.Q. Chen, M.Y. Ma, H.L. Liu, R.D.K. Misra, Mater. Chem. Phys. 205, 508 (2018)

[10] W. Du, L. Jiang, Q. Sun, Z. Liu, X. Zhang, J. Iron. Steel Res. Int. 17, $58(2010)$

[11] X. Zhang, L.J. Fan, Y. Xu, J. Li, X. Xiao, L.Z. Jiang, Mater. Des. 65, $682(2015)$

[12] H.L. Liu, M.Y. Ma, L.L. Liu, L.L. Wei, L.Q. Chen, Acta Metall. Sin. 55, 566 (2019)

[13] H.F.G. Abreu, A.D.S. Bruno, S.S.M. Tavares, R.P. Santos, S.S. Carvalho, Mater. Charact. 57, 342 (2006)
[14] F. Gao, Z.Y. Liu, H.T. Liu, G.D. Wang, Acta Metall. Sin. -Engl. Lett. 24, 343 (2011)

[15] GB/T 228.1-2010, Metallic materials-Tensile testing-Part 1: Method of test at room temperature, China Standard Press, 2010

[16] GB/T 5027-2016, Metallic materials-Sheet and strip-Determination of plastic strain ratio, China Standard Press, 2016

[17] X. Zhang, L.J. Fan, Y.L. Xu, J. Li, X.S. Xiao, L.Z. Jiang, Mater. Des. 9, 626 (2016)

[18] P. Ghosh, R.R. Chromik, B. Vashegi, A.M. Knight, J. Magn. Magn. Mater. 365, 14 (2014)

[19] F. Gao, F.X. Yu, R.D.K. Misra, X.J. Zhang, S.M. Zhang, Z.Y. Liu, J. Mater. Eng. Perform. 24, 3862 (2015)

[20] C.W. Sinclair, F. Robaut, J.D. Mithieux, J.H. Schmitt, Y. Brechet, Adv. Eng. Mater. 5, 570 (2003)

[21] Y. Bai, T. He, Y.D. Liu, Mater. Charact. 137, 142 (2018)

[22] G.J. Cai, C.S. Li, D.G. Wang, Y.K. Zhou, Mater. Charact. 141, $169(2018)$

[23] J.X. Li, Z.Y. Liu, C.R. Gao, Z.D. Wang, X.H. Liu, G.D. Wang, J. Mater. Process. Technol. 167, 132 (2005)

[24] J.W. Fu, F. Li, J.J. Sun, Y.C. Wu, Mater. Sci. Eng. A 738, 335 (2018)

[25] L. Xu, F. Barlat, D.C. Ahn, J.D. Bressan, Mater. Sci. Eng. A 528, $3113(2011)$

[26] W. Du, L.Z. Jiang, Q.S. Sun, Z.Y. Liu, X. Zhang, J. Iron. Steel Res. Int. 17, 47 (2010)

[27] H.J. Shin, J.K. An, S.H. Park, D.N. Lee, Acta Mater. 51, 4693 (2003)

[28] X.G. Ma, J.W. Zhao, W. Du, X. Zhang, L.Z. Jiang, Z.Y. Jiang, Mater. Sci. Eng. A 685, 358 (2017)

[29] C. Zhang, Z.Y. Liu, G.D. Wang, J. Mater. Process. Technol. 211, $1051(2011)$

[30] X.G. Ma, J.W. Zhao, W. Du, X. Zhang, Z.Y. Jiang, Mater. Charact. 137, 201 (2018) 